\title{
Texture analysis of computed tomographic images in osteoporotic patients with sinus lift bone graft reconstruction
}

Hélène Marchand-Libouban ${ }^{1}$,Bernard Guillaume ${ }^{2}$, Norbert Bellaiche ${ }^{3}$, Daniel Chappard ${ }^{1 *}$.

${ }^{1}$ LUNAM Université, GEROM- LHEA « Bone remodeling and biomaterials » - IRISIBS Institut de Biologie en Santé, CHU d'Angers, 49933 ANGERS Cedex -FRANCE.

${ }^{2}$ CFI, Collège Français d'Implantologie, 6 rue de Rome, 75008 PARIS - FRANCE

Centre d'Imagerie numérisée Saint Germain, 9 rue Montalembert, 75007 PARIS France

e-mail: daniel.chappard@ univ-angers.fr

doi: $10.1007 / \mathrm{s} 00784-012-0808-\mathrm{z}$

Key words: sinus lift; $\beta$-TCP; bone graft; texture analysis; CT-scan; image analysis.

\begin{abstract}
Objective: Bone implants are now widely used to replace missing teeth. Bone grafting (sinus lift) is a very useful way to increase the bone volume of the maxilla in patients with bone atrophy. There is a 6-9 mo. delay for the receiver grafted site to heal before the implants can be placed. Computed tomography is a useful method to measure the amount of remaining bone before implantation and to evaluate the quality of the receiver bone at the end of the healing period. Texture analysis is a non-invasive method useful to characterize bone microarchitecture on X-ray images.

Patients and methods: Ten patients in which a sinus lift surgery was necessary before implantation were analyzed in the present study. All had a bone reconstruction with a combination of a biomaterial ( $\beta$-TCP) and autograft bone harvested at the chin. Computed tomographic images were obtained before grafting $(\mathrm{t} 0)$, at mid-interval $(\mathrm{t} 1$ : $4.2 \pm 0.7$ mo.) and before implant placement (t2: $9.2 \pm 0.6$ mo.). Texture analysis was done with the run-length method.

Results: A significant increase of texture parameters at t1 reflected a gain of homogeneity due to the graft and the beginning of bone remodeling. At $t 2$, some parameters remained high and corresponded to the persistence of bone trabeculae while the resorption of biomaterials was identified by other parameters which tended to return to pre-graft values.

Conclusion: Texture analysis identified changes during the healing of the receiver site. Clinical relevance: The method is known to correlate with microarchitectural changes in bone and could be a useful approach to characterized osseointegrated grafts.
\end{abstract}


Texture analysis and bone graft

Clin Oral Investig. 2013 May;17(4):1267-72

\section{Introduction}

Correction of teeth loss in the posterior areas of the jawbones can be obtained by a removable prosthesis. Nevertheless, for several decades the rehabilitation by implants and prostheses has allowed to rebuild a fixed dental arch to avoid the discomfort of removable dentures. However, initial stabilization of implants is difficult to achieve in the posterior maxillary regions where cortical bone is thin and immediately under the sinus [1]. Posterior loss of teeth at the maxilla is often associated with a very thin bone floor due to a pneumatization of the sinus, a post-extraction bone atrophy of alveolar ridges or a parodontal bone resorption [2,3]. Some authors have suggested not intervening directly at the sinusal level by using either implants posed at distance (pterygo-jawbone or zygomatic) [4], with short implants or lateral insertion [5]. These indications remain limited and seldom used.

When the floor of the maxillary sinus above the alveolar ridge is thinner than $8-10 \mathrm{~mm}$ it is difficult to obtain an effective and durable implant anchorage. In this case, it is recommended to increase the bone volume of the sinus $[6,7]$. The majority of surgical teams has recourse to sinus augmentation (or sinus lift) by filling with a variable volume of material [8]. A lateral osteotomy on the external face of the maxillary sinus is done (usually $10 \mathrm{~mm}$ in length and $8 \mathrm{~mm}$ in height) with a diamond drill under irrigation. The mucous membrane lining the sinus (Schneiderian membrane) on the other side of the window is gently pushed up and away from the bone to avoid perforation. Granules of bone-graft material are then inserted and packed into the space where the sinus was, under the membrane. The amount of material to graft may vary, but usually several millimeters of bone are added above the jaw to reconstitute a suitable bone volume that can support the installation of implants. If the residual height of bone of the sinus floor is higher than $5 \mathrm{~mm}$ one can consider the simultaneous installation of implants at the time of the graft because a primary anchoring of the implant is obtained. If the height is lower than $5 \mathrm{~mm}$, the surgeon will proceed in two times by the installation of the implants once the graft has healed.

Computed tomography (CT) is a useful clinical method to measure the amount of remaining bone before implantation and also to evaluate the size of the grafted area in a few months after implantation and the quality of the receiver bone at the end of the healing period [9]. Texture analysis of X-ray images is a non-invasive method that is useful to characterize bone microarchitecture on images coming from different X-ray devices $[10,11]$. The aim of this study was to analyze, by texture analysis, the grafted area on repetitive CT scans of patients having had a sinus lift elevation with a mixture of beta tricalcium phosphate ( $\beta$-TCP) and autograft. This was done in search of objective measurements before implant placement.

\section{Patients and methods}

Patients and surgical protocol

This study is consistent with the ethical principles enunciated from the Declaration of Helsinki. Ten patients who presented a partial edentulation at the maxilla and who were 
candidate for implant placement after a bone graft were enrolled in the study. The following general exclusion criteria were applied: diabetes, active malignancy, previous long term treatment with bisphosphonate. Each has given her/his informed consent to participate in the present study. The protocol was approved by the French Collège of Implantology (CFI-Paris \#2011-1). The surgical protocol aimed at increasing the thickness of the sinus floor by using a combination of autograft (usually 20-30\% Volume/Volume) and $\beta$-TCP granules (70-80\%). The thickness of the sinus floor was appreciated on CT scans (General Electric ${ }^{\mathrm{TM}}$ Highspeed $^{\circledR}$ and Lightspeed ${ }^{\circledR}$ Advantage models, with $100 \mathrm{~mA}, 100 \mathrm{kV}, 0.6 \mathrm{~mm}$ helical acquisitions, voxel side $250 \mu \mathrm{m}$, reformations through $5^{\text {th }}$ to $9^{\text {th }}$ versions of Simplant ${ }^{\circledR} C T / M a s t e r^{\circledR}$ softwares) before sinus lift elevation before surgery $(\mathrm{t} 0)$. A second $\mathrm{CT}$ scan was performed at mid-course, at $4.2 \pm 0.7$ months post grafting ( $\mathrm{t} 1)$. A third control CT scan was performed before the placement of dental implants of standard diameter around $9.2 \pm 0.6$ months (t2). The ANARA principle (As Low As Reasonably Achievable) was considered before starting the study [12]. The dose delivered by the CTscan is in the order of 530-2100 $\mu \mathrm{Sv}$. The common natural irradiation is about $2.5 \mathrm{mSv} / \mathrm{y}$ and the maximal radiation admissible is $50 \mathrm{mSv} / \mathrm{y}$.

All patients were grafted by the same surgeon (BG) who used the same protocol. The bone graft was harvested in first at the chin as previously reported [13]. Briefly, samples of cortico-trabecular bone were removed at the mandible symphysis. The limits of the harvesting graft areas were done with a thin bur and the graft was separated with a chisel by a progressive cleavage. Chips of cortico-trabecular bone were obtained and mixed with the patient's blood together with $\beta$-TCP granules (Kasios ${ }^{\mathrm{TM}}$, Launaguet, France) to obtain a kind of paste that could be handled more easily.

The grafted area was prepared as follows: the mucoperiosteal flap was removed after a lateral osteotomy on the external face of the maxillary sinus (usually the opening is $10 \mathrm{~mm}$ in length and $8 \mathrm{~mm}$ in height). The Schnederian membrane was gently pushed through the window, away from the bone to avoid perforation. The mixture containing autograft particles, $\beta$-TCP and blood was inserted into the void space, under the membrane. The amount of material used depended on the patient but usually, several millimeters of the grafting "paste" were added to reconstitute a suitable volume that will support the placement of implants after healing. The full thickness flap was then closed to the primary incisions, and sutured with $5 / 0$ vicryl.

Texture analysis

From each stack of CT images in the tif format, at least 6 images (comprising the whole grafted area) were selected when the cross-sectional reconstruction slice was perpendicular to the cortical plate of one side of the maxilla. Texture analysis was performed using Mazda, software specially designed for texture analysis of magnetic resonance images by Materka and coworkers (Politechnika Institute of Electronics, Lodz, Poland). A region of interest (ROI) was interactively drawn on the grafted area and served as a mask for the texture analysis study. The run-length distribution method was selected. Briefly, on a grey level image, pixels range from 0 (black) to 255 (White). The consecutive pixels of the same grey value in a given direction constitute a run [14, 15]. The run length parameters have been extensively described elsewhere and comprise $[14,15]$ : 
- RLNRun Length Non-uniformity measures the similarities of the length of the runs throughout the image. The RLN is expected small if the run lengths are alike throughout the image.

- GLN - Grey Level Non-uniformity measures the similarity of grey level values throughout the image. The GLN is expected small if the grey level values are alike throughout the image.

- SRE - Short Run Emphasis is highly dependent on the occurrence of short runs and is expected large for fine textures.

- LRE - Long Run Emphasis is highly dependent on the occurrence of long runs and is expected large for coarse structural textures.

For a detailed description of these parameters, see [16]. The software computes the parameters in the horizontal and vertical directions and the mean of all images was considered for analysis. Because the grafted zone has an isotropic distribution of bone trabeculae and grafted particles, the average of each parameter measured in the both direction was considered. The data were standardized so that the initial value at t0 equals 0 for all patients. The values of $\mathrm{t} 1$ and $\mathrm{t} 2$ are expressed as $\%$ of change in comparison to $\mathrm{t} 0$.

Statistical analysis

Statistical analysis was done using the Systat statistical software, release 13 (Systat, San José, CA). All results are expressed as mean \pm standard error of the mean (SEM). The Kruskall-Wallis non parametric analysis of variance was used to compare the differences between the groups. Comparison between groups was obtained by the Dwass-Steel-Chritchlow-Fligner post-hoc test. Differences were considered significant at $\mathrm{p}<0.05$.

\section{Results}

The mean age of the patients was $65.5 \pm 9.9$ years. They were analyzed by the same radiologist (NB) with the same $\mathrm{CT}$ and the same softwares. The mean age of patients and times for $\mathrm{t} 1$ and $\mathrm{t} 2$ post-surgery appear on table 1 . $\mathrm{t} 1$ was performed at $4.2 \pm 0.7$ mo. and t 2 at $9.2 \pm 0.6$ mo. post-surgery.

\begin{tabular}{lllll} 
Patient\# & Gender & Age at t0 & t1 (in mo.) & t2 (in mo.) \\
\hline 1 & M & 64 & 2 & 6 \\
2 & F & 58 & 3 & 8 \\
3 & F & 73 & 5 & 9 \\
4 & F & 61 & 5.5 & 10.5 \\
5 & F & 73 & 6 & 11 \\
6 & F & 63 & 5 & 11 \\
7 & F & 46 & 3 & 8 \\
8 & F & 80 & 2 & 7.5 \\
9 & F & 62 & 8 & 12.5 \\
10 & F & 75 & 2 & 9 \\
\hline
\end{tabular}

Table 1: Characteristics of patients enrolled in the present study. 
All patients were clinically evaluated at $\mathrm{t} 2$ and were implanted shortly after their third CT scan examination. Sequences of typical images of this series appear on Fig. 1 which depicts the aspects of the grafted site containing both allograft fragments and $\beta$-TCP granules which appear more radio opaque than cancellous bone. A marked increase in radiodensity is noticeable at $\mathrm{t} 1$ when the grafted materials have induced the proliferation of new trabeculae. At $\mathrm{t} 2$, the amount of grafted material seems to have considerably decreased on CT scans and the texture of the grafted area resembles that of cancellous bone although some remnants of allogeneic bone or biomaterial can still be evidenced. At the time of implant placement, some remnants of $\beta$-TCP could be observed macroscopically. At the time of implant placement, some remnants of $\beta$-TCP could be observed macroscopically.

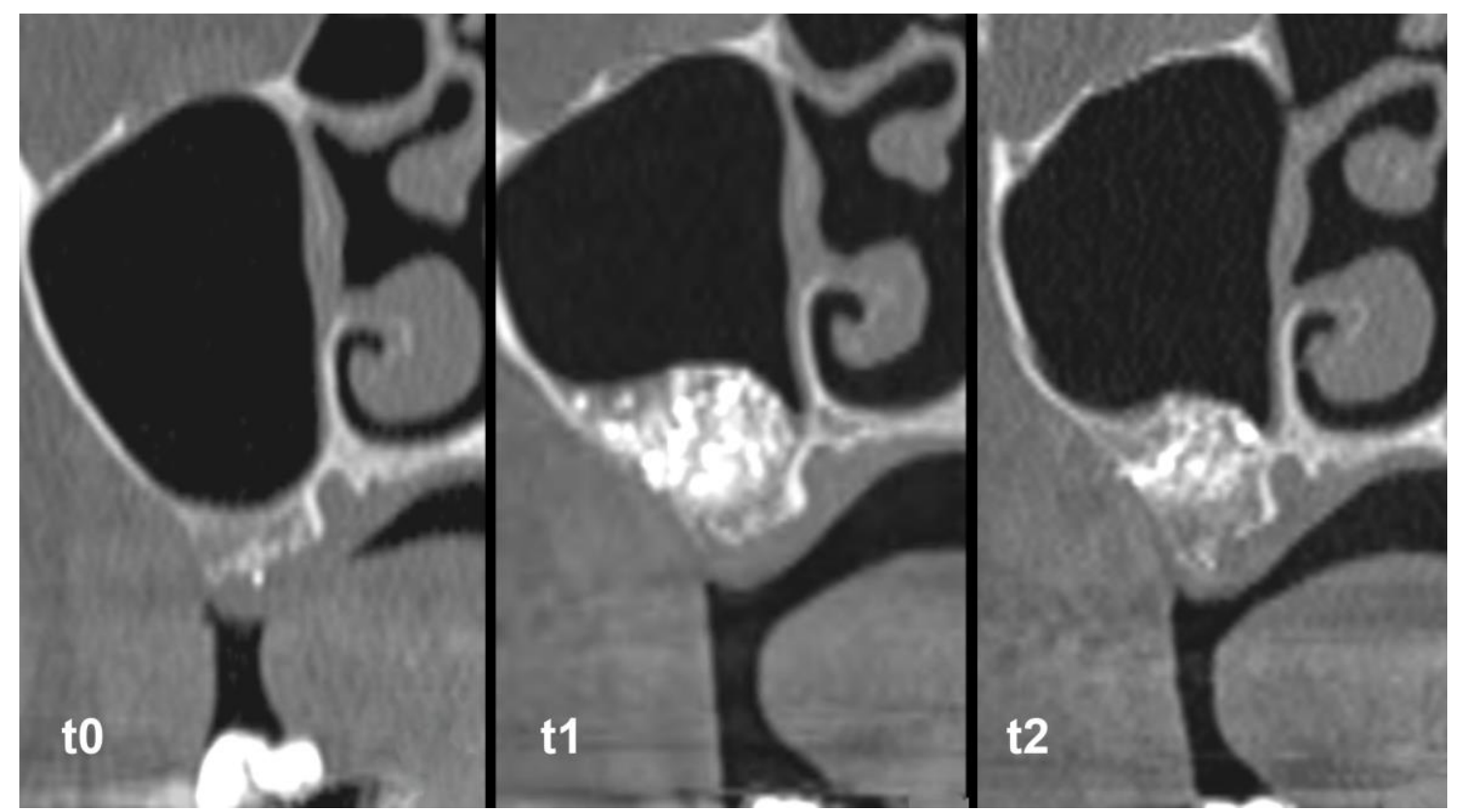

Figure 1 : Time sequence series of the grafted area in a patient having received a graft composed of $\beta$-TCP and allogenic bone.Note the densification of the area at $t 1$ and the reduction of radio-opacity at $t 2$ when the texture appears less coarse.

Texture analysis quantified the variations in the structure of the grafted area. At t1, RLN was considerably increased in all patients $(\mathrm{p}<0.0001 v s \mathrm{t} 0)$; this corresponded both to the presence of the two types of biomaterials grafted but also to the development of new trabeculae between the grafted particles. GLN was also significantly increased in all patients $(\mathrm{p}<0.0001 \mathrm{vs} \mathrm{t} 0)$, corresponding to the presence of the more radio-opaque materials ( $\beta$-TCP and bone chips). SRE increased non significantly at $\mathrm{t} 1$ and LRE was significantly increased $(\mathrm{p}<0.006 v s \mathrm{t} 0)$ due the the presence of biomaterial remnants. At $\mathrm{t} 2$, RLN remained high in the majority of the patients; this corresponded to the development of more and more bone trabeculae which can be evidenced on some CT sections (Fig. 2). On the other hand, GLN had a marked tendency to decrease, a finding that could be explained by the reduction in size of the more radio-opaque particles of $\beta$-TCP and cortical bone chips but the difference with 1 did not reach significance. SRE continued to increase due to the presence of numerous thin new trabeculae. RLE returned to the t0 values, indicating the restauration of a 
cancellous microarchitecture similar to the ungrafted bone at t0 with the disappearance of the long runs due to the material particles.
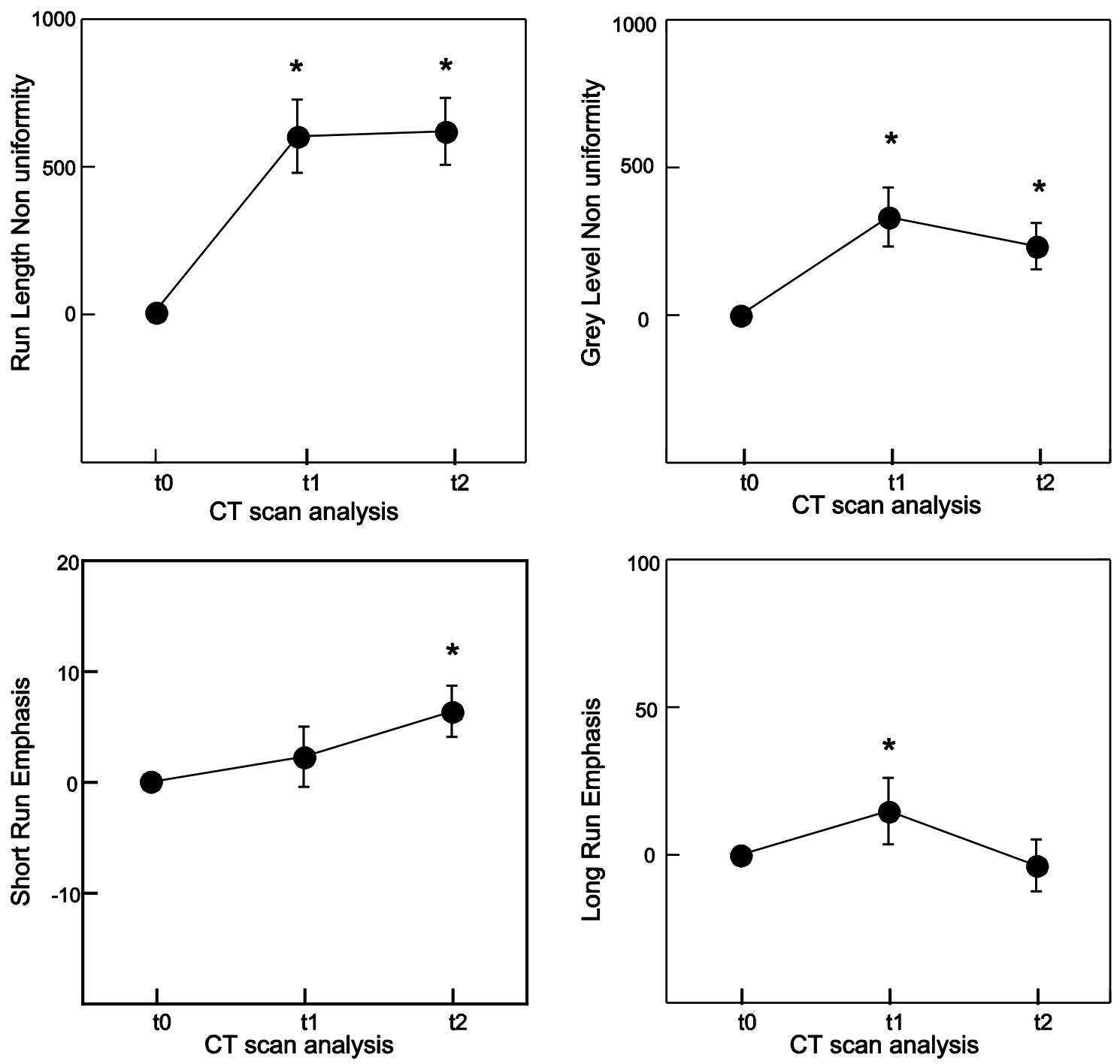

Figure 2 : Time evolution of run-length parameters in the patients. All results are expressed as percentage of change versus t0; *: significant from value at t0.

\section{Discussion}

The nature of filling material used in sinus augmentation has evolved during the last decades: initially, autograft was the only possibility. The bone is usually harvested from the parietal bone [17, 18], ilium, tibia [19] or the chin [13, 20]. The cortical bone of the graft is used to separate the upper part of the new sinus cavity. The lower part is usually filled by trabecular bone. The morbidity of autograft bone harvesting is now well recognized, the wish to limit the volume of harvested bone, the need for filling greater volumes has led many teams to evaluate other materials such as allogeneic [21], xenogeneic bone [22, 23] or synthetic biomaterials (hydroxyapatite, calcium phosphates, bio glass) [24]. For some authors, filling can be done with a single 
biomaterial; for others it is preferable to use a mixture of autograft and biomaterial (primarily harvested from the chin because of the surgical facility); no consensus exists at that time [25]. In this case, the volume of the bone autograft which has to be harvested remains moderate, about 1 to $1.5 \mathrm{~cm}^{3}$. The respective proportion of the autograft mixture/biomaterial is currently not the subject of any consensus. The use of autogenic bone is most often recommended because it is commonly thought that bone cells of the graft can survive the transplant and favor osseointegration of the graft [13, 26]. Variations in the amount of allograft material and especially the amount of cortical bone chips may vary. Ideally, it would have been interesting to compare the texture analysis just after the bone graft, since $\mathrm{t} 1$ represents an intermediary step when resorption of the biomaterials and occurrence of new trabeculae has started. The remodeling of the grafted bone and biomaterials necessitates at least a 6 month period before placing the implants. However, as previously shown, the $\beta$-TCP material has not completely disappeared in all patients even after 6-9 months post-surgery and remnants can be found incorporated in bone trabeculae [27, 28]. There is a noticeable delay necessary for the receiver grafted site to heal (about 6 months) before the implants can be placed.

In this series, a variation in the texture parameters was observed at t0 that could reflect the various bone status of the patients at the beginning of the study. It is likely that variations in the amount of bone mass and bone microarchitecture are altered in this series of patients by local bone atrophy or osteoporosis. Texture analysis has been reported to be a powerful tool to appreciate bone microarchitecture in 2D on X-ray or CT images in osteoporotic patients [11, 29-31]. The texture analysis parameters have been found to correlate well with bone histomorphometry and microCT parameters of bone microarchitecture $[10,11]$. For this reason, in order to standardize the results, all parameters were set to 0 at $\mathrm{t} 0$ and variations at $\mathrm{t} 1$ and $\mathrm{t} 2$ were expressed as percentage changes. At t1, a marked increase in RLN and GLN was noted and reflects the replacement of both biomaterials together with colonization of the grafted area by the centripetal growth of new trabeculae [27, 32-35]. Since it is not possible to obtain a CT-scan in the immediate post-surgery period, the importance of newly-formed bone (together with the fraction of biomaterial resorbed) cannot be exactly appreciated. On the other hand, at $\mathrm{t} 2$, RLN remained high, a finding that can be explained by the persistence of long runs due to new trabeculae. SRE became significantly increased at t2 due to the development of thin newly-formed bone trabeculae. GLN tended to decrease with the resorption of the more radio-opaque materials, giving less coarse images. Taken together, these parameters indicated a tendency to a "return to a normal bone microarchitecture" with the disappearance of the grafted materials and the occurrence of newly formed bone. The amount of bone formed after $\beta$-TCP grafting has been shown to remain quite stable after 4.5-9 mo. and when the period is extended for more than 9 mo. [36]. In the present study, t1 was chosen because it was hypothesized that the association of autograft and $\beta$-TCP could accelerate bone healing and the texture analysis represented an objective and non-invasive method to quantify the bone changes. 
Texture analysis and bone graft

Clin Oral Investig. 2013 May;17(4):1267-72

\section{Conclusion}

Texture analysis is a powerful tool in the examination of X-ray or CT images. In this series, it was used to characterize the evolution of the grafted zone during a sinus lift surgery using a combination of $\beta$-TCP granules and allogenic bone chips. After an increase at $\mathrm{t} 1$, there was a progressive decrease of some parameters evaluating the regularity of the texture while some parameters, influenced by the development of new trabeculae, remained at high levels in the grafted area. The method can be proposed to quantify the evolution of the texture of the grafted site and to decide the time of implant placement when coarse structures have almost disappeared. Due to the recent development of the cone beam CT scan, this method could be a useful help to the surgeon to confirm the healing of the grafted site. Furthermore, the radiation dose received will be considerably reduced since the given values are in the range of 40-1070 $\mu \mathrm{Sv}$ [37].

\section{Acknowledgments}

This work was made possible by grants from Contrat de Plan Etat - Région "Pays de la Loire" Bioregos2. The $\beta$-TCP was provided by Kasios (Launaguet, France). Thanks to Mrs. L. Lechat for secretarial assistance. 


\section{References}

1. Marquez S (2008) The paranasal sinuses: the last frontier in craniofacial biology. Anat Rec 291:1350-1361

2. Bodic F, Hamel L, Lerouxel E, Baslé MF, Chappard D (2005) Bone loss and teeth. Joint Bone Spine 72:215-221

3. Bodic F, Amouriq Y, Gayet-Delacroix M, Maugars Y, Hamel L, Basle MF, Chappard D (2012) Relationships between bone mass and micro-architecture at the mandible and iliac bone in edentulous subjects: a dual X-ray absorptiometry, computerised tomography and microcomputed tomography study. Gerodontology 29, e585-e594, 2012.

4. Linkow LI, Mahler MS (1976) Three year progress report on the pterygoid extension implant for the totally and partially, edentulous maxillae. Dent Digest 7:9-17

5. Nedir R, Bischof M, Briaux JM, Beyer S, Szmukler-Moncler S, Bernard JP (2004) A 7-year life table analysis from a prospective study on ITI implants with special emphasis on the use of short implants. Results from a private practice. Clin Oral Implants Res 15:150-157

6. Smiler DG, Johnson PW, Lozada JL, Misch C, Rosenlicht JL, Tatum OH, Jr., Wagner JR (1992) Sinus lift grafts and endosseous implants. Treatment of the atrophic posterior maxilla. Dent Clin North Am 36:151-188

7. Kahnberg KE, Nilsson P, Hirsch JM, Ekestubbe A, Gröndahl K (2001) Sinus lifting procedure. Clin Oral Implants Res 12:479-487

8. Zinner ID, Small SA (1996) Sinus-lift graft: using the maxillary sinuses to support implants. J Am Dent Assoc 127:51-57

9. Schwartz Z, Goldstein M, Raviv E, Hirsch A, Ranly DM, Boyan BD (2007) Clinical evaluation of demineralized bone allograft in a hyaluronic acid carrier for sinus lift augmentation in humans: a computed tomography and histomorphometric study. Clin Oral Implants Res 18:204-211

10. Chappard D, Guggenbuhl P, Legrand E, Basle MF, Audran M (2005) Texture analysis of X-ray radiographs is correlated with bone histomorphometry. J Bone Miner Metab 23:24-29

11. Guggenbuhl P, Bodic F, Hamel L, Baslé MF, Chappard D (2006) Texture analysis of X-ray radiographs of iliac bone is correlated with bone micro-CT. Osteoporosis Int 17:447-454

12. Farman AG (2005) ALARA still applies. Oral surgery, oral medicine, oral pathology, oral radiology, and endodontics 100:395-397

13. Guillaume B, Gaudin C, Georgeault S, Mallet R, Baslé MF, Chappard D (2009) Viability of osteocytes in bone autografts harvested for dental implantology. Biomed Mater 4:15012

14. Galloway MM (1975) Texture analysis using gray level run lengths. Comput Graph Image Proc 4:172-179

15. Chu A, Sehgal CM, Greenleaf JF (1990) Use of gray value distribution of run lengths for texture analysis. Patt Recogn Lett 11:415-419

16. Szczypinski PM, Strzelecki M, Materka A, Klepaczko A (2009) MaZda--a software package for image texture analysis. Comput Methods Programs Biomed 94:66-76 
Texture analysis and bone graft

Clin Oral Investig. 2013 May;17(4):1267-72

17. Abubaker AO, Sotereanos GC, Patterson GT (1992) Cranial bone harvesting. In Bell W (ed) Modern practice in orthognathic and reconstructive surgery. Saunders Philadelphia, pp 975-984

18. Jung YS, Kim HJ, Choi SW, Kang JW, Cha IH (2003) Regional thickness of parietal bone in Korean adults. Int J Oral Maxillofac Surg 32:638-641

19. Askew CA, Fleming PS, Downie IP (2005) Adjunctive use of dental implants in mandibular reconstruction with a free fibular graft. Br J Oral Maxillofac Surg 43:341-342

20. Widmark G, Andersson B, Ivanoff CJ (1997) Mandibular bone graft in the anterior maxilla for single-tooth implants. Presentation of surgical method. Int J Oral Maxillofac Surg 26:106-109

21. Haas R, Haidvogl D, Dortbudak O, Mailath G (2002) Freeze-dried bone for maxillary sinus augmentation in sheep. Part II: biomechanical findings. Clin Oral Implants Res 13:581-586

22. Papa F, Cortese A, Maltarello MC, Sagliocco R, Felice P, Claudio PP (2005) Outcome of 50 consecutive sinus lift operations. Br J Oral Maxillofac Surg 43:309-313

23. Galindo-Moreno P, Ávila G, Emilio Fernández-Barbero JE, Aguilar M, SánchezFernández E, Cutando A, Wang HL (2007) Evaluation of sinus floor elevation using a composite bone graft mixture. Clin Oral Implants Res 18:376-382

24. Giannoudis PV, Dinopoulos H, Tsiridis E (2005) Bone substitutes: an update. Injury 36 Suppl 3:S20-27

25. Wheeler SL, Holmes RE, Calhoun CJ (1996) Six-year clinical and histologic study of sinus-lift grafts. Int J Oral Maxillofac Implants 11:26-34

26. Burchardt H (1983) The biology of bone graft repair. Clin Orthop Relat Res 174:28-42

27. Chappard D, Guillaume B, Mallet R, Pascaretti-Grizon F, Baslé MF, Libouban H (2010) Sinus lift augmentation and beta-TCP: a microCT and histologic analysis on human bone biopsies. Micron 41:321-326

28. Guillaume B, Libouban H, Baslé MF, Chappard D (2010) Comblement sinusien par B-TCP avant pose d'implants chez l'homme : étude clinique et histologique. Titane 7:201-210

29. Cortet B, Chappard D, Boutry N, Dubois P, Cotten A, Marchandise X (2004) Relationship between computed tomographic image analysis and histomorphometry for microarchitectural characterization of human calcaneus. Calcif Tissue Int 75:23-31

30. Pothuaud L, Benhamou CL, Porion P, Lespessailles E, Harba R, Levitz P (2000) Fractal dimension of trabecular bone projection texture is related to threedimensional microarchitecture. J Bone Miner Res 15:691-699

31. Buckland-Wright JC, Lynch JA, Macfarlane DG (1996) Fractal signature analysis measures cancellous bone organisation in macroradiographs of patients with knee osteoarthritis. Annals of Rheumatic Diseases 55:749-755

32. Nyangoga H, Aguado E, Goyenvalle E, Baslé MF, Chappard D (2010) A nonsteroidal anti-inflammatory drug (ketoprofen) does not delay beta-TCP bone graft healing. Acta Biomater 6:3310-3317

33. Horch HH, Sader R, Pautke C, Neff A, Deppe H, Kolk A (2006) Synthetic, purephase beta-tricalcium phosphate ceramic granules $\left(\right.$ Cerasorb $\left.^{\circledR}\right)$ for bone 
Texture analysis and bone graft

Clin Oral Investig. 2013 May;17(4):1267-72

regeneration in the reconstructive surgery of the jaws. Int J Oral Maxillofac Surg 35:708-713

34. Knabe C, Koch C, Rack A, Stiller M (2008) Effect of beta-tricalcium phosphate particles with varying porosity on osteogenesis after sinus floor augmentation in humans. Biomaterials 29:2249-2258

35. Kondo N, Ogose A, Tokunaga K, Ito T, Arai K, Kudo N, Inoue H, Irie H, Endo N (2005) Bone formation and resorption of highly purified beta-tricalcium phosphate in the rat femoral condyle. Biomaterials 26:5600-5608

36. Klijn RJ, Meijer GJ, Bronkhorst EM, Jansen JA (2010) A meta-analysis of histomorphometric results and graft healing time of various biomaterials compared to autologous bone used as sinus floor augmentation material in humans. Tissue Eng Part B Rev 16:493-507

37. Guerrero ME, Jacobs R, Loubele M, Schutyser F, Suetens P, van Steenberghe D (2006) State-of-the-art on cone beam CT imaging for preoperative planning of implant placement. Clin Oral Investig 10:1-7 